\title{
A IMPORTÂNCIA DA COMUNICAÇÃO NAS ORGANIZAÇÕES
}

\author{
Adriana Cristina Silva ${ }^{4}$ \\ Wanderley Cesar Pedrosa ${ }^{5}$ \\ Lucas Hernane Andrade Leonel ${ }^{6}$ \\ DOI NUMBER: 10.33726/akedia2447-7656v5a42018p37-54 \\ Tiago Cesar de Lacerda Florêncio ${ }^{7}$
}

RESUMO: O conceito de comunicação é fortemente influenciado pelas transações entre as pessoas, de tal modo que a comunicação constitui a primeira área a ser focalizada na administração de Recursos Humanos. Cada vez mais os líderes das organizações precisam estar atentos à rapidez das mudanças no cenário político, econômico e social, bem como a velocidade dos avanços tecnológicos. Hoje os clientes estão mais exigentes e atualizados com a acessibilidade das informações, portanto, o termo qualidade não é mais um diferencial, é uma obrigação. A visão da empresa e suas atitudes é que irão atrair os clientes externos e internos que se identificam com ela, gerando vários aspectos positivos como: transparência, confiança e lealdade. Os líderes, no entanto, precisam reconhecer a comunicação como algo estratégico na gestão coorporativa, onde agrega valores a produtos e serviços. É através dela que conseguimos formar uma verdadeira equipe harmoniosa e motivada a promover interação e o relacionamento entre as pessoas e os departamentos. As organizações que reconhecem a comunicação como algo competitivo, constroem sua imagem institucional e credibilidade pública, estreitando um relacionamento ético e de responsabilidade social. O presente artigo abordará o tema através de pesquisas bibliográficas onde será analisada a importância da comunicação nos relacionamentos, objetivos e desenvolvimento da organização. Atualmente, os fluxos de comunicação estão se intensificando em todos os sentidos, trazendo relevância num contexto amplo de discussões que envolvem aspectos teóricos e conceituais do qual fazem parte.

PALAVRAS-CHAVE: Comunicação, Organização. Gestão de Pessoas. Administração.

ABSTRACT: The concept of communication is strongly influenced by the transactions between people, so that communication is the first area to be focused on the administration of Human Resources. Increasingly, organizational leaders need to be aware of the rapid changes in political, economic and social as well as the speed of technological advances. Today customers are more demanding and updated with the accessibility of information, hence the term quality is no longer a differential is a must. The company's vision and their attitude is that will attract external and internal customers to identify with it, generating several positive aspects such as transparency, trust and loyalty. The leaders, however, need to recognize communication as

\footnotetext{
${ }^{4}$ Economista, docente na UEMG - Universidade do Estado de Minas Gerais, Unidade Frutal. Contato: adrianacriss@yahoo.com.br.

${ }^{5}$ Assistente Social, UNESP - Franca -SP. Contato: wanderleypedrosa@yahoo.com.br.

6 Administrador, Graduado pela Faculdade de Frutal _ FAF. Contato: lucashernane1994@hotmail.com.

${ }^{7}$ Discente do $1^{\circ}$ período do Curso de Jornalismo da UEMG - Universidade do Estado de Minas Gerais, Unidade Frutal. Contato: tiago bod@hotmail.com.
} 
something strategic in corporate management, which adds value to products and services. It is through her that we can form a true harmonious team and motivated to promote interaction and relationship between people and departments. Organizations that recognize the communication as something competitive, build their corporate image and public credibility, narrowing an ethical and social responsibility. This article will address the theme through literature searches which will analyze the importance of communication in relationships, goals and organization development. Currently, the communication flows are increasing in all directions, bringing relevance in a broader context of discussions involving theoretical and conceptual aspects to which they belong.

KEYWORDS: Communication. Organization. Personnel Management. Management.

\section{INTRODUÇÃO}

A comunicação nas organizações é uma arma essencial para a sobrevivência das empresas no mercado competitivo atual. Essa ferramenta estabelece um relacionamento entre a empresa e os funcionários, permitindo que eles acompanhem as suas principais ações e verifiquem o impacto de suas tarefas no alcance dos resultados traçados, responsável pela motivação dos colaboradores e para o sucesso da organização.

A comunicação constitui uma relação muito abrangente nas organizações, pois é um fator fundamental dentro do ambiente de trabalho, além de facilitar a motivação estimula ao crescimento, pois esclarece aos seus funcionários o que deve ser feito, para melhorar e suas qualidades, deve ser uma ferramenta de administração estratégica nos mais variados níveis hierárquicos para atingir o sucesso da organização.

Nessa perspectiva, a sua prática não é responsabilidade de um departamento específico, mas sim de todos que os compõem a empresa, desde gestores a subordinados. Somente dessa forma, podem-se evitar ruídos e conflitos que atrapalhem o bom relacionamento interpessoal no ambiente de trabalho.

Atualmente, oferecer produtos e serviços com qualidade é uma obrigação das empresas. Seu diferencial está em valorizar o capital humano através de uma comunicação desenvolvida para os colaboradores. Assim, compreender a importância de praticar esse processo constitui um desafio para as empresas, pois a sabe-se que a sua ineficiência pode prejudicar o 
crescimento nas organizações e trazer prejuízos e transtornos em toda empresa.

O presente estudo se propõe analisar o processo de comunicação dentro das organizações para identificar os pontos fortes e fracos dentro do ambiente de trabalho para que não influencie no seu crescimento. Além disso, o trabalho aponta os estilos de comunicação que afetam no desempenho das pessoas e equipe, permitindo alcançar resultados expressivos e impulsionar a produtividade, onde cada indivíduo deve-se sentir responsável pelo sistema como um todo e não apenas pela atribuição individual e possa satisfazer suas necessidades.

\section{COMUNICAÇÃO}

A comunicação é a forma de se expressar e relacionar entre si, trocando informações, ideias e experiência com diversas pessoas dentro de uma organização, além de argumentar qualquer tipo de problema de trabalho. É uma das principais ferramentas motivadoras para seus funcionários, pois esclarece a eles o que deve ser feito, e o que fazer para melhorar.

Para MATOS (2014, p. 02) "A palavra comunicação é uma derivação do termo latino Communicare que significa; partilhar, tornar comum". Ou seja, a comunicação é um conjunto de várias formas de expressão, fala, gestos, interpretações, compreensão, seja dentro das organizações ou fora, a comunicação é o elo entre emissor que emite uma mensagem e o receptor que recebe a informação.

Para Bordenave e Carvalho 1979, "a comunicação refere-se ao processo natural, universal, de inter-relação e influência de troca entre as partes de uma organização e entre esta e seu ambiente". Uma comunicação mal recebida pode ocasionar diversos fatores, a mensagem que o emissor envia para o receptor pode-se distorcer e devemos tomar cuidado com ruídos que atrapalham a informação. Para viver na sociedade, grupos são de extrema importância para que em qualquer âmbito se atinja seus objetivos.

Segundo Chiavenato (2003, p.109), “as pessoas não vivem isoladas e nem são autossuficientes. Elas se relacionam continuamente com outras 
pessoas e seus ambientes através da comunicação." O ser humano não consegue viver sem a comunicação, ele necessita comunicar-se com alguém, em qualquer lugar através da fala ou sinais. Embora a comunicação constitua uma das capacidades humanas mais fundamentais e seu desenvolvimento nos indivíduos se dê de forma que pode ser considerada natural, a verdade é que a grande maioria das pessoas não sabe comunicar-se.

Muitas pessoas confundem informar com comunicar. Segundo Gil (2001, p. 71) "informar é um ato unilateral, que envolve a pessoa que tem uma informação a dar, enquanto, comunicar implica tornar algo comum, fazer-se entender e provocar reações no interlocutor". Informar resume-se em uma pessoa que passa informação sobre determinado assunto, sem preocupar com os receptores após receber a informação. Enquanto comunicar é uma troca de diálogo entre emissor e receptor onde vai trocar opiniões sobre determinado assunto, enfim, o ato comunicativo envolve interação entre os envolvidos, e não apenas um fluxo unidirecional de transmissão da informação.

Quando a organização contrata um novo membro para sua empresa, essa tem que ter uma cultura organizacional já pronta, para que ele possa entender a comunicação da empresa, é necessário que a organização passe todas as informações sobre seu trabalho a ser cumprido, para que não haja nenhuma falha na sua comunicação.

Bowditch e Buono (1992, p. 80), definem comunicação, "como sendo a troca de informações entre um transmissor e um receptor, e a inferência (percepção) do significado entre indivíduos envolvidos, é um processo pelo qual conduzimos nossas vidas". Comunicação é a forma de transparência ao passar as informações, que são emitidas em constância por todos os seres humanos, envolve participação de todas as partes, o retorno das informações é o feedback, essa relação acontece a todo momento, na vida e no cotidiano de todos.

O processo da comunicação inicia-se com o Emissor: que é um dos atores responsável pela emissão da comunicação. Codificação: $O$ ato de conversão de uma mensagem em linguagem, Segundo Robbins (2014) essa conversão é perceptível pela habilidade, conhecimento e cultura. Mensagem: É em si o objeto da comunicação, notícia ou recado sendo verbal ou escrito. Robbins (2014, p. 385) discorre que: "Canal: é o meio pelo qual cada 
mensagem trafega que é selecionada pelo destinatário Decodificação: É a interpretação de uma mensagem emitida pelo receptor. Receptor: é um dos atores que recebe a mensagem, aquele que recebe a informação e a decodifica e a interpreta. Por fim, temos o feedback que é o retorno, que leva o comportamento após a interpretação da informação".

Para a realização de um processo de comunicação podemos utilizar o modelo de Shannon-Weaver do processo de comunicação dos quais destacamos:

Informação (processo ou equipamentos que fornece as mensagens a serem enviadas); Transmissor (processo ou equipamento que codifica a mensagem e a transmite ao canal); Canal (equipamento ou espaço intermediário entre transmissor e receptor onde a mensagem será passada); Receptor (processo ou equipamento que recebe e decodifica a mensagem); Destino (a pessoa, processo ou equipamento a quem é destinada a mensagem) e por fim Ruído (perturbações indesejáveis que tendem a alterar e distorcer, de maneira imprevisível, a mensagem).

Vale destacar que de acordo com o modelo proposto pela Teoria Matemática da Comunicação, o ruído é algo que atrapalha a recepção da mensagem, fazendo com que a mesma não leve informação certa às pessoas. É tudo que interfere na comunicação prejudicando assim a mensagem.

Para Vanoye (1998), os ruídos são "designados por tudo o que afeta, em graus diversos, a transmissão da mensagem, não se aplicando apenas a perturbação de ordem sonora, mas tudo a que se aplica a comunicação".

\section{TIPOS DE COMUNICAÇÃO}

A comunicação é uma ferramenta que interfere diretamente na performance global de uma empresa, sem a sua utilização, as empresas dificilmente conseguiriam delinear planos estratégicos para a realização dos objetivos e funcionar numa perspectiva holística.

Poder-se-á dizer que a comunicação assume uma importância fundamental nas dinâmicas internas e externas de uma empresa, contribuindo para uma mais fácil interação e desempenho dos indivíduos. Nesta 
perspectiva, a comunicação assenta em duas funções essenciais para a sua atividade global, que são a promoção e a coordenação da comunicação interna e externa.

$\mathrm{Na}$ comunicação externa compreende toda a informação que esteja relacionada com as atividades que esta empresa desenvolve. Essa informação vai no sentido de promover a imagem da empresa, normalmente através de divulgação na imprensa dos acontecimentos que a empresa realiza. Essas ações são desenvolvidas em torno da gestão da sua imagem institucional e estão associadas às temáticas e aos conceitos que as formalizam, ou seja, a comunicação externa é importante na empresa, pois através dela você capta e mantêm seus clientes. Enquanto a comunicação interna pode ser entendida como toda a atividade desenvolvida em contexto organizacional que é responsável pela produção e fluxo de informação entre os atores organizacionais e que está inerente a toda a atividade desenvolvida pelos mesmos. Neste âmbito destacam-se, sobretudo as atividades de seleção e distribuição de notícias, a produção e gestão de conteúdos multimídia, a organização de atividades de formação como seminários e workshops e ainda a concepção e elaboração de propostas relacionadas com o desenvolvimento cultural.

Seguindo as ideias de SANTOS (2003, p. 01) observa-se que:

A comunicação envolve muito mais do que apenas palavras. As palavras são apenas uma pequena parte da nossa capacidade de expressão como seres humanos. Estudos demonstram que numa apresentação diante de um grupo de pessoas: $55 \%$ do impacto da comunicação são determinados pela linguagem corporal; $38 \%$ pelo tom de voz; $7 \%$ apenas pelas palavras e conteúdo da apresentação.

Para que a comunicação aconteça nas empresas, os responsáveis pelo envio das informações, chamados de emissores podem utilizar linguagens verbais e não verbais. Estas podem ser definidas como:

Verbais: Pode ser sonora (linguagem falada, ordens, pedidos e conversas) ou visual (linguagem escrita por meio das cartas, telegramas, dos cartazes, dos livros, jornais ou revistas). Não verbais: Comunicação feita por meio de sinalização, logotipos, ícones, gestual, expressões faciais, dentre outras. 
Nota-se que os tipos de comunicação mais utilizados nas organizações são: a comunicação escrita e a oral, presentes dentro das comunicações verbais. De acordo com Blikstein, citado por Tomasi (2010, p. 88) "a eficácia da comunicação escrita depende de três elementos básicos: produzir uma resposta, tornar o pensamento comum aos outros e persuadir". Ainda seguindo suas ideias "muitas mensagens escritas pecam pela mistura de assuntos, pela confusão de ideias, e pior ainda pela diluição do objetivo".

As principais comunicações escritas são as correspondências de modo geral (Carta comercial, Memorando, ofício, circular, requerimento, telegrama, email), fax, barra de holerite, manual de integração quadro de avisos, jornalmural, cartaz/banner, caixa de sugestões, mala direta, folheto, folder, flyer, volante, newsletter, teaser, entre outros. Já a comunicação oral é muito frequente nas organizações, em conversas, entrevistas, reuniões, treinamentos e telefonemas (linguagem escrita por meio das cartas, telegramas, dos cartazes, dos livros, jornais ou revistas).

A comunicação oral: estabelece-se por meio do intercomunicador, ou do telefone (interno ou externo), em que a palavra e a voz são fundamentais. A comunicação direta: estabelece-se sempre que somos confrontados com outra pessoa, ou numa conversa cara a cara, reunião ou palestra, onde a voz e a palavra são reforçadas ou diminuídas, mediado pelo intercomunicador, ou do telefone (interno ou externo), em que a palavra e a voz são fundamentais. $E$ por fim a Comunicação escrita: determina-se que seja como o exterior ou interior através de anúncios ou cartas, circulares. É utilizada para transmitir uma mensagem sem apresentar dúvidas de interpretação, pois o emissor não está presente.

A comunicação é um processo pelo qual a informação é codificada e transmitida por um emissor a um receptor por meio de um canal ou médio prazo. A comunicação é, portanto, um processo pelo qual nós atribuímos e transmitimos significado em uma tentativa de criar entendimento compartilhado. $\mathrm{Na}$ organização os tipos de comunicação se adequam para que seja possível atingir seus objetivos. 


\section{CANAIS DE COMUNICAÇÃO}

Os meios de comunicação e a sua própria evolução são importantes, pois os levam a refletir sobre a nossa própria evolução. É certo que se fizermos uma análise consciente da forma como os meios de comunicação têm vindo a evolui de dia para dia, podemos admitir que isso só acontece porque o ser humano também tem vindo a evoluir graças aos estudos e pesquisas que elabora, o que garante também um avanço na área da tecnologia que por sua vez irá criar condições para a melhoria e avanço das necessidades e do bem estar do Ser Humano.

Tendo em conta esta perspectiva de evolução, e a importância de comunicação, o ser Humano valoriza e por isso investe nos meios de comunicação, pois, estes, são considerados artifícios que permitem a comunicação entre pessoas, contribuindo com o processo de transmissão de informações. E esta é a verdadeira importância dos meios de comunicação.

Visto que o destinatário pode ter várias reações ao que está sendo transmitido nas empresas pelos comunicadores, que serão todos, devendo ter cautela ao se transmitir uma comunicação, no caso dos gerentes, coordenadores, diretores, ou seja, profissionais que têm outros sob sua orientação o cuidado é, e deve ser maior, eles devem mensurar o grau de entendimento de seus comunicados, caso contrário corre-se o risco de não se obter os resultados esperados através dos mesmos.

Os destinatários recebem as mensagens através de canais ao se analisar os canais utilizados por uma organização, podemos destacar: Os canais ou meios de informação são classificados em relação à capacidade de transmitir informação mais ou menos rica, com a riqueza diminuindo na sequência, a saber (DAFT, 1997):

1. meio mais rico é o face a face, que é caracterizado pela riqueza das expressões adicionais como linguagem não-verbal e proporciona um feedback imediato para possíveis correções; por isso, esse tipo de canal permite diminuir ao máximo a ambiguidade no processo da comunicação; 
2. o telefone (fixo ou móvel) e outros meios eletrônicos pessoais de comunicação formam o segundo grupo mais rico, pois o feedback é rápido, as mensagens são direcionadas pessoalmente e com recursos adicionais como a entonação, porém as expressões visuais não podem ser transmitidas;

3. documentos escritos, endereçados pessoalmente (cartas, notas, faz, e-mails etc.) têm riqueza menor ainda; o feedback é mais lento e as expressões/indicações visuais são mínimas (figuras, gráficos, esquemas, fontes diferentes como negrito, itálico etc.);

4. documentos escritos, endereçados pessoalmente (boletins, relatórios, bancos de dados de computador) são mais "enxutos" (menos ricos), geralmente eles são mais quantitativos, não necessariamente proporcionam feedback e servem bem para transmitir dados exatos para muitas pessoas.

Vemos que estes canais são meios de comunicação utilizados para se transmitir informação em uma empresa. A escolha do canal de informação a ser utilizado depende, não somente, do que se vai transmitir como também do: resultado que se quer alcançar e do feedback quer se quer ter. Ao analisarmos as ações e reações do receptor da mensagem se não for satisfatório ao que se esperava, a culpa não necessariamente é do receptor, mas do transmissor que não tomou as devidas cautelas ao se comunicar.

Com isto percebemos o quanto é importante conhecer todos os componentes que faz parte de uma comunicação eficaz, não importa se a comunicação será escrita, oral ou gestual. A atenção deve ser a mesma para toda a comunicação, pois dela depende o sucesso ou o não sucesso de uma organização.

\section{4 - BARREIRAS PARA UMA COMUNICAÇÃO EFICAZ}

Em toda comunicação existem barreiras que precisam ser identificadas para que a comunicação seja transmitida com qualidade facilitando o processo eficaz do processo de comunicação. Essas barreiras variam de organizações para organizações. 
Segundo Davis e Newstrom (2004, p. 09), "mesmo quando o receptor recebe a mensagem e realmente se esforça para decodificá-la, existe um grande número de interferências que podem limitar sua boa compreensão, estes obstáculos atuam como barreiras à comunicação".

A filtragem é a manipulação deliberada da informação, para fazer com que ela pareça mais favorável para o receptor. Por exemplo, quando um administrador diz ao seu chefe o que ele quer ouvir, ele está utilizando a filtragem de informação. A quantidade de filtragem tende a ser proporcional ao tamanho da estrutura da organização e da cultura organizacional. Quanto mais níveis verticais existirem na organização, maiores serão as oportunidades para a filtragem. A cultura organizacional pode incentivar ou desestimular a filtragem, através do tipo de comportamento que ela reforça através das recompensas. Quanto mais as recompensas organizacionais reforçarem o estilo e a aparência, mais os administradores estarão motivados para alterar as comunicações em seu favor.

Emoções, a forma como um receptor se sente quando a mensagem é recebida influencia o modo como a interpreta. Você muitas vezes irá interpretar a mesma mensagem de forma diferente, dependendo de estar feliz ou não. Emoções extremas, como alegria ou depressão, têm grande chance de atrapalhar a comunicação eficaz. Em tais casos, muitas vezes se despreza os processos de pensamento racional e objetivo e se utiliza julgamentos emocionais. Dessa forma, é melhor evitar em tomar decisões quando se está nervoso, já que há poucas chances de pensar de forma clara.

O medo da comunicação é outra grande barreira da comunicação eficaz, muitas pessoas deixam de falar em público, por medo da comunicação oral, sofrem ansiedades dificultando assim o processo da mensagem.

Além disso, é considerado um fator agravante a uma boa comunicação, os indivíduos que sofrem com algum tipo de inibição ou timidez, quase sempre temem a uma comunicação oral.

Para Bowditch e Buono (1992, p. 85), as principais barreiras à comunicação são:

Sobrecarga de informações: a sobrecarga se refere a uma situação onde tenhamos mais informações do que somos capazes de ordenar e utilizar. 
- Tipos de informações: as informações que se encaixarem em nosso conceito tendem a ser recebidas e aceitas muito mais prontamente do que dados que venham a contradizer o que já sabemos. Fontes de informações: como algumas pessoas contam com mais credibilidade que as outras, tema tendência a acreditar nessas pessoas e desconfiar de informações recebidas de outras. Localização física e distrações: a localização física e a proximidade entre transmissor e receptor também influencia a eficácia da mensagem. $O$ boato dentro das empresas é uma das barreiras da comunicação por ser um fator que influencia e muito dentro das organizações, por distorcer uma comunicação e assim colocando em risco toda a comunicação da organização.

Robbins (2014, p. 279), coloca como barreira à comunicação:

Filtragem a filtragem: refere-se a manipulação da mensagem pelo emissor, para que ela seja vista da maneira mais favorável pelo receptor. Percepção seletiva: o receptor no processo de comunicação vê e escuta seletivamente, com base em suas próprias necessidades, motivações, experiências, histórico e outras variáveis. Defesa: quando as pessoas se sentem ameaçadas, a tendência é uma reação para reduzir a capacidade de entendimento mútuo. Linguagem: as palavras têm significados diferentes para pessoas diferentes. 0 significado das palavras não está nelas, e sim em nós.

Qualquer tipo de barreira atrapalha uma comunicação. Para que aja uma comunicação sem barreiras é importante que os gestores das empresas estejam atentos as suas organizações, e conheça melhor os seus receptores.

As barreiras, ruídos ou interferências são fatores inibidores da eficácia da comunicação, descaracterizando a mensagem e o objetivo pretendido. Kunsch (2003, p. 74) classifica as barreiras como "gerais ou comuns, que podem ser de natureza mecânica, fisiológica, semântica ou psicológica”. As barreiras mecânicas ou físicas estão relacionadas com os aparelhos de transmissão, como ambientes e equipamentos inadequados que podem dificultar ou impedir seu fluxo. Pode também ser bloqueada por fatores físicos (telefone com defeito, ambiente de trabalho desorganizado, entre outros). No âmbito organizacional, segundo Kunsch (2003), as barreiras são pessoais; administrativas/burocráticas; excesso e sobrecarga de informações; e informações incompletas. Numa organização, a falta de entendimento entre aquele que planeja e aquele que executa pode acarretar grandes prejuízos. 
Dê acordo com Vasconcellos e Hemsley (2003), enfoca que, os problemas da comunicação como uma das principais fraquezas das estruturas de organizações tradicionais, e são mais graves à medida que o nível hierárquico aumenta, podendo assim distanciar a comunicação das diretrizes da organização para os níveis inferiores desta. A Comunicação eficaz passa pela necessidade de sintetizar a comunicação fragmentada, que promove a cultura informal, podendo influenciar no sucesso no gerenciamento de projetos.

\section{COMUNICAÇÃO ORGANIZACIONAL E SUAS FORMAS DE COMUNICAÇÃO}

A comunicação organizacional abrange todas as formas de comunicação utilizadas pela organização para relacionar-se e interagir com seus públicos. Para o ambiente de uma organização é indispensável, como uma comunicação bem estabelecida as organizações se juntam, para que consiga cumprir suas atividades em conjunto.

Comunicar de forma eficaz para uma organização não é tarefa fácil devido à complexidade do ser humano, sua história de vida, seus valores, sua cultura, enfim sua subjetividade. A Comunicação Organizacional é composta por: Comunicação Institucional (Relações Públicas); Comunicação Interna (Comunicação Administrativa) e Comunicação Mercadológica (Marketing), que segundo Kunsch (1997, p. 116) pode ser administrada sob uma mesma direção:

Para as organizações em geral, é muito importante a integração de suas atividades de comunicação, em função do fortalecimento do conceito institucional, mercadológico e corporativo junto a toda a sociedade. É preciso incorporar a ideia de uma comunicação globalizante, que nos ajude a compreender e acompanhar o ritmo acelerado das mudanças no Brasil e no mundo. Uma combinação parcial e fragmentada nunca conseguirá isso.

De maneira geral, a comunicação organizacional é toda e qualquer ação, atividade, estratégia, produto e processo tomados pela empresa ou entidade para reforçar a sua imagem junto a todos os seus públicos de interesse - 
consumidores, colaboradores, políticos, empresários e acionistas, entre outros, ou perante a opinião pública. Para Kunsch (2003, p. 149):

Comunicação organizacional, como objeto de pesquisa, é a disciplina que estuda como se processa o fenômeno comunicacional dentro das organizações no âmbito da sociedade global. Ela analisa o sistema, o funcionamento e o processo de comunicação entre a organização e seus diversos públicos. (...) Fenômeno inerente aos agrupamentos de pessoas que integram uma organização ou a ela se ligam, a comunicação organizacional configura as diferentes modalidades comunicacionais que permeiam sua atividade.

Seguindo esta filosofia, a comunicação organizacional é composta por todas as formas de comunicação dentro de uma organização: a comunicação institucional, a comunicação interna, a comunicação administrativa e a comunicação mercadológica.

Kunsch (2003, p. 152) aponta o composto da comunicação integrada:

Comunicação Interna: Comunicação Administrativa (fluxos) Redes formal e informal (veículos) entrelaçam com a comunicação Institucional e a comunicação Mercadológica: Institucional é as relações públicas, jornalismo empresarial, assessoria de imprensa, editoração multimídia, imagem corporativa, propaganda institucional, marketing social e cultural. E a Mercadológica é: marketing, propaganda, promoção de vendas, feiras e exposições, marketing direto, merchandising e venda pessoal.

Assim, podemos compreender que a Comunicação Organizacional identifica e integra os diferentes tipos de comunicação, possibilitando a unificação de processos comunicacionais. Em nossos estudos chamamos de ferramentas da comunicação tudo que esta dentro da gestão do setor de Comunicação Organizacional. 


\section{A COMUNICAÇÃO NA ADMINISTRAÇÃO DAS ORGANIZAÇÕES E AMBIENTE DE TRABALHO}

Os seres humanos são obrigados a colaborar uns com os outros, formando organizações para alcançar certos objetivos que a ação individual não conseguiria alcançar. Pode-se dizer que organizações são sistemas de atividades coordenadas por mais de duas pessoas que cooperam entre si e só existem quando:

a) Há pessoas capazes de se comunicarem; b) Que estão dispostas a trabalhar em conjunto; c) E, a fim de alcançar objetivo em comum.

A comunicação organizacional é de extrema importância para às organizações, pois visa passar informações, tomadas de decisões corretas e desenvolver relacionamentos que integram e coordenam todas as partes.

O comportamento humano nas organizações sofre influências pessoais (personalidade, motivação, expectativas, objetivos pessoais) e ambientais (cultura, ambiente de trabalho).

As relações humanas estão voltadas para atitudes e ações desenvolvidas com os grupos e pessoas. Toda pessoa procura entrar em grupo e ser aceita e compreendida de forma a seguir seus interesses e aspirações.

Cada pessoa tem uma personalidade que pode ser influenciada por outro indivíduo ou grupo. A compreensão dessas relações contribui para melhorar a produtividade dos empregados, porque pode falar de uma forma mais espontânea e de uma maneira sadia. Neto (2001, p. 57) aponta que:

O comportamento humano é resultado de um conjunto de fatos coexistentes, que podem ser entendidos como um campo de forças dinâmico inter-relacionado. Portanto, o comportamento de uma pessoa depende não somente de suas experiências passadas, mas também do meio ambiente psicológico atual.

O foco das organizações é enfrentar a competitividade e sobreviver às novas exigências do mercado. No passado, a comunicação organizacional tinha como função apenas estabelecer elos de relacionamentos com o emissor e receptor. 
Segundo Bueno (1995, p.9), diz que "Hoje, não se pode imaginar uma empresa que se pretenda ser líder de mercado e que volte às costas para o trabalho de comunicação".

A mudança é difícil, pois pessoas são influenciáveis e cada qual desenvolve um comportamento perante os processos de comunicação.

Segundo Nassar (2004, p. 31), afirma que:

Aos gestores cabe prestar atenção as mudanças na sociedade e antecipar-se a um modelo diferente de relacionamento. A auto-estima dos trabalhadores, o sentimento de identidade com a organização, a responsabilidade com o trabalho, a produtividade e a competitividade, entre outros indicadores, com certeza, não são estimuladas por uma comunicação interna que os despreza ou subestima.

A comunicação pode e deve ser utilizada para estimular, motivar e melhorar a imagem da empresa, mas sua prioridade nas organizações é solucionar problemas, gerar e facilitar a compreensão entre pessoas com diferentes pontos de vista. Kwasnicka (1995, p.17) discorre que:

A comunicação interage na hierarquia da empresa, sendo o fator que pode construir ou destruir a imagem, os relacionamentos e os objetivos. Para o autor, qualquer pessoa ou grupo que tenham a intenção de iniciar um negócio próprio, precisa ter o conhecimento para administrar, ou então, contratar alguém para fazê-lo, visto que os problemas decorrentes do negócio devem ser previstos para alcançar a finalidade principal.

A comunicação se bem administrada oferece a qualquer empresa agilidade. Os administradores começaram a se preocupar com os aspectos "intangíveis" da organização, tais como liderança, comunicação, motivação, organização informal, buscando entender o comportamento humano e encontrar soluções para os problemas organizacionais. 


\section{CONCLUSÃO}

A Comunicação tem se transformado significativamente nestes últimos anos, algumas ferramentas utilizadas pela mesma podem até ser parecidas, mas não iguais, pois encontramos em cada profissional uma forma única de observá-la. Não encontramos em seu uso, ferramentas erradas, mas sim inadequadas. Todas as ferramentas são empregáveis contanto que seja necessária a sua utilização, que será bem mais eficaz se a necessidade de seu uso em uma determinada organização. Os gestores devem conhecer as ferramentas e as utilizá-las de forma construtiva, de nada adiantará o uso de uma ferramenta mal utilizada, pois o seu conteúdo pode ser mal interpretado e não alcançar os resultados esperados. A partir de resultados não esperados muitos gestores, até mesmo por falta de conhecimento e experiência, podem pensar que a ferramenta que não dá resultados, onde na verdade foi a forma como ela foi utilizada. Por este motivo no momento da utilização da mesma fazse necessário realizar estudos e descrever os indicadores que serão utilizados como referência para mensurar os resultados das mesmas.

As ferramentas utilizadas pela comunicação são dinâmicas, únicas, momentâneas quando faladas, mas eternas quando escritas. São capazes de tudo quando entendidas ou de nada quando não compreendida.

A integração das ferramentas de comunicação se dá a partir do momento em que se tem uma visão sistêmica dos resultados que se quer alcançar pela organização. Gestão se faz com comunicação, não se pode pensar em gestão sem comunicação, portanto muitos gestores ao avaliar um processo poderiam ter maior proveito se avaliassem através da falta ou da forma como foi utilizada a comunicação ao invés de ficar tentando encontrar erros em pessoas, tecnologia, conhecimentos técnicos. Os gestores devem intensificar as ações voltadas para a comunicação dentro de sua organização, independente do porte ou segmento da mesma, pois todos os que fazem parte da organização tem a necessidade de se comunicar quer seja para obter ou dar informação.

A Comunicação é um diferencial que não tem preço, pois cada um tem um jeito de se comunicar, cada empresa tem sua forma de ser, sua imagem é criada através da comunicação. Educar através da comunicação, ser a 
comunicação, promover a comunicação, receber comunicação, são ações que todos fazemos inconscientemente em todos os momentos de nossas vidas.

Esperamos que as discussões apresentadas desperte em cada leitor uma necessidade de avaliação e análise dos seus conhecimentos e da importância que o mesmo tem dado aos estudos voltados para área de Comunicação, pois estes conhecimentos somados aos conhecimentos técnicos proporcionarão o alcance ao crescimento pessoal e profissional do mesmo, quer seja na sua vida pessoal ou profissional.

\section{REFERÊNCIAS}

BORDENAVE, Juan Diaz; CARVALHO, Horácio Martins de. Comunicação e planejamento. 2. ed. Rio de Janeiro: Paz e Terra, 1979. 5. ed. São Paulo: Atlas, 1995 BOWDITCH, James L e BUONO, Anthony F. Elementos de comportamento organizacional. Tradução de Jose Henrique Lamendorf. São Paulo: Pioneira, 1992.

BUENO, Wilson da Costa. Comunicação Empresarial: teoria e pesquisa. São Paulo, Editora Manole, 2003.

CHIAVENATO, Idalberto. Administração de recursos humanos: fundamentos básicos. 5. ed. São Paulo: Atlas, 2003.

DAFT, R. I. Administração. Trad. Fernando Gastaldo Morales. 4. ed. Rio de Janeiro: LTC, 1997.

DAVIS, Keith e NEWSTROM, Jhon W. Comportamento humano no trabalho: uma abordagem organizacional. Tradução de Eunice Laçava Kwasmicha. São Paulo: Pioneira Thomson, 2004.

GIL, Antonio Carlos. Gestão de pessoas: enfoque nos papéis profissionais. São Paulo: Atlas, 2001.

KUNSCH, Margarida Maria Krohling. Planejamento de relações públicas na

Comunicação Integrada. 3. ed. São Paulo: Summus, 1986.

KWASNICKA, E. L. Introdução à Teoria Geral da Administração. São Paulo, Ed. Atlas, 1995.

MATOS, Gustavo Gomes de. Comunicação empresarial sem complicação. 3ํㅡㄹ Edição. Barueri - SP: Manole, 2014.

NASSAR, Paulo. Tudo é comunicação. São Paulo: Lazuli Editora, 2004.

NETO, João P. de Barros. Teoria da Administração. Manual Prático para Organizacional. Tradução de José Henrique Lamendorf. São Paulo: Pioneira, 1992. 
ROBBINS, Stepen, P. Comportamento organizacional. São Paulo: São Paulo, 2010.

SANTOS, Eliane. Comunicação efetiva através de e-mail. Disponível em: http://www.institutovencer.com.br/images/Sessoes/27/Comunica\%C3\%A7\%C3\%A30\% 20por\%20e-mail.pdf. Acesso em 05/09/2017.

TOMASI, C. MEDEIROS, J. Comunicação empresarial. São Paulo: Atlas, 2010.

VANOYE, Francis. Usos da linguagem: problemas e técnicas na produção oral e escrita. 11 ed. São Paulo: Martins Fontes, 1998.

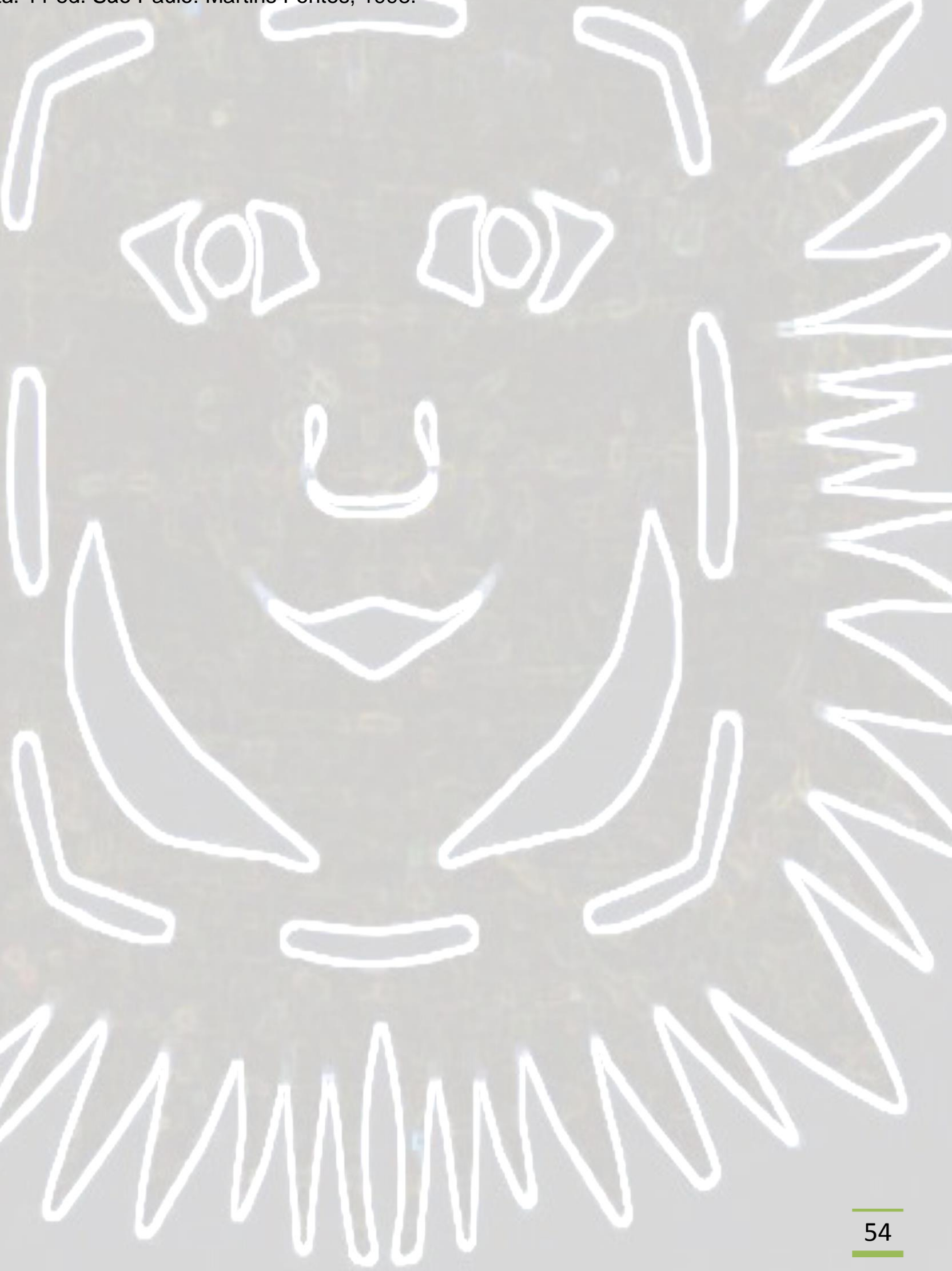

